Vol. 6, No. 1 Januari - Juni 2017

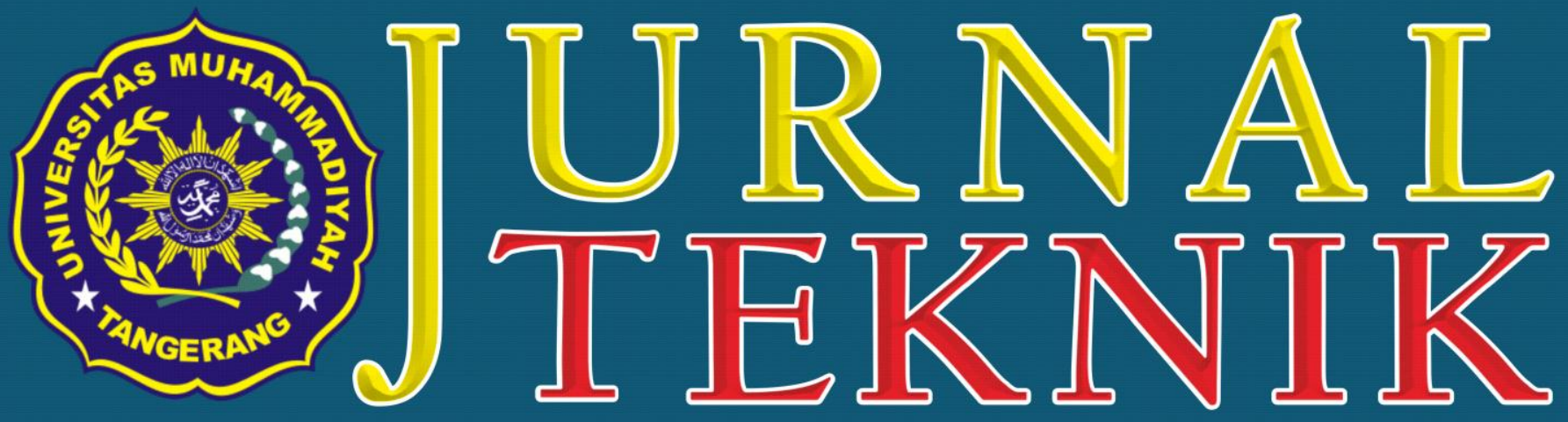

Alamat Redaksi: Jl. Perintis Kemerdekaan I No. 33, Cikokol Tangerang - TIp. (021) 51374916

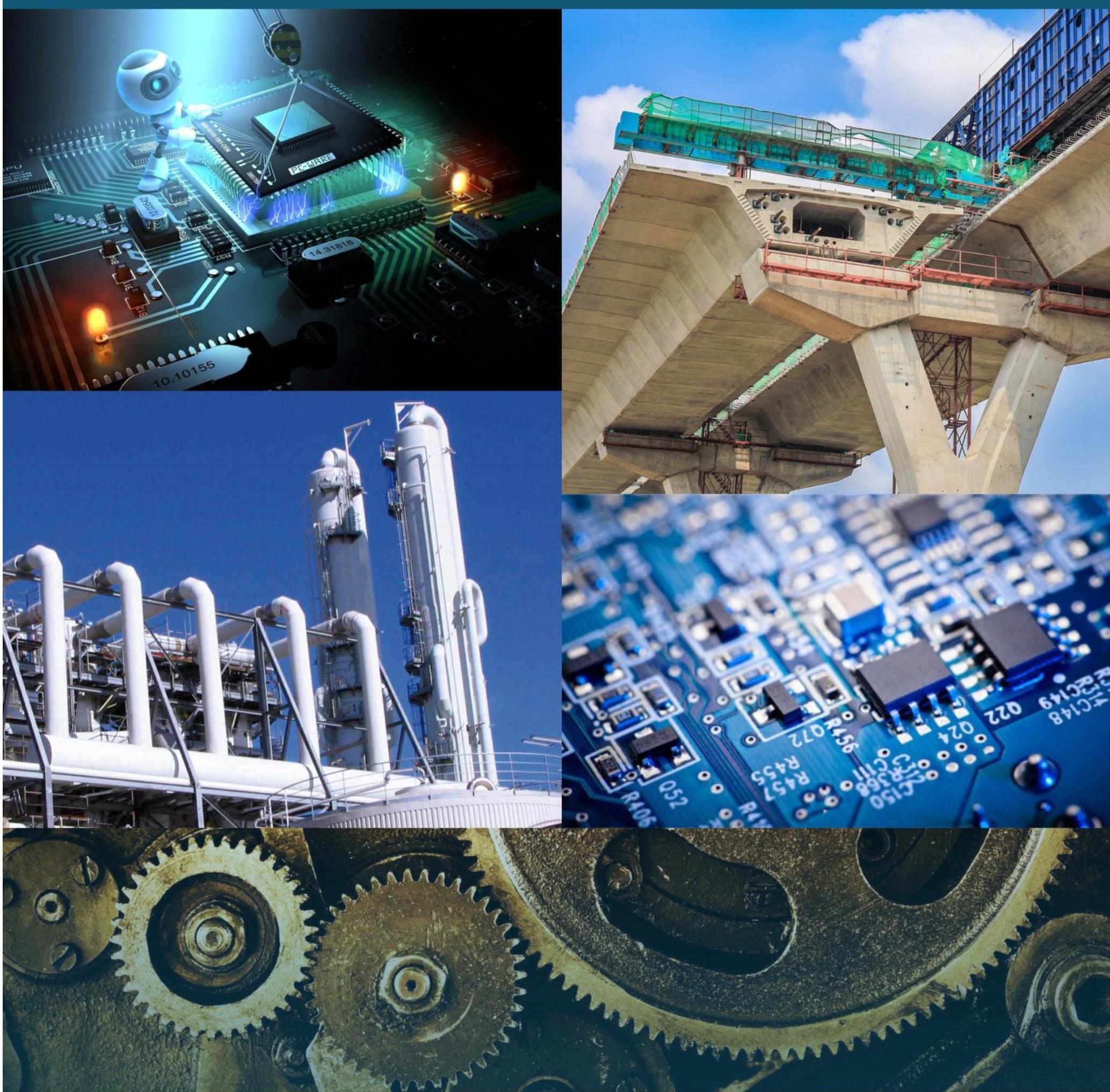




\section{J U R N A L TEKN I K}

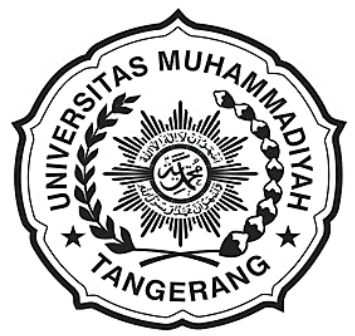

\section{UNIVERSITAS MUHAMMADIYAH TANGERANG}

Pelindung:

Dr. H. Achmad Badawi, S.Pd., SE., MM. (Rektor Universitas Muhammadiyah Tangerang)

Penanggung Jawab:

Ir. Saiful Haq, ST., M.Si.

(Dekan Fakultas Teknik)

Pembina Redaksi:

Rohmat Taufik, ST., M.Kom.

Drs. H. Syamsul Bahri, MSi.

Pimpinan Redaksi:

Ir. Sumardi Sadi, S.Pd., ST., MT.

Redaktur Pelaksana:

Yafid Efendi, ST, MT.

Editor Jurnal Teknik UMT:

Ir. Sumardi Sadi, S.Pd., ST., MT.

Dewan Redaksi:

Ir. Ali Rosyidin, ST., MM., MT.

Tri Widodo, ST.,MT.

Tina Herawati, ST., MT

Almufid, ST., MT.

Siti Abadiah, ST., MT.

M. Jonni, SKom., MKom.

Syepry Maulana Husain, S.Kom., M.Kom.

Ir. H. Bayu Purnomo, ST., MT

Kasubag:

Ferry Hermawan, MM.

Keuangan:

Elya Kumalasari, S.Ikom.

Setting \& Lay Out:

Muhlis, S.E

Saiful Alam, SE.

Mitra Bestari:

Prof. Dr. Aris Gumilar

Ir. Doddy Hermiyono, DEA

Dr. Ir. Budiyanto, MT.

Dr. Alimuddin, ST., MM., MT

J U R N A L T E K N I K

Diterbitkan Oleh:

Fakultas Teknik Universitas Muhammadiyah Tangerang

Alamat Redaksi:

Jl. Perintis Kemerdekaan I No. 33, Cikokol Tangerang Tlp. (021) 51374916

\begin{tabular}{|c|c|c|c|c|c|}
\hline \multirow{2}{*}{$\begin{array}{c}\text { Jurnal } \\
\text { Teknik }\end{array}$} & 6 & 1 & $1-97$ & $\begin{array}{c}\text { Jan'-Juni } \\
2017\end{array}$ & ISSN \\
\cline { 2 - 6 } & $2302-8734$ \\
\hline
\end{tabular}

\section{DAFTAR ISI}

1. PROSES PEMBUATAN ALAT PEMBUKA KALENG CAT DENGAN METODE CETAK PASIR (SAND CASTING) - 1-11 Ali Rosyidin

2. ANALISA DAN PERANCANGAN SISTEM KENDALI PLC XBC MINI BAS - 12-18 Alim Hardiansyah \& Bambang Suardi Waluyo

3. PENGATUR KESTABILAN SUHU PADA EGG INCUBATOR BERBASIS ARDUINO - 19-22

Abel Putra Hidayah \& Sumardi Sadi

4. METODE PEMBUATAN PONDASI BORE PILE DENGAN KINGPOST DAN METODE PONDASI DINDING PENAHAN TANAH DIAFRAGMA WALL - 23-29

Almufid

5. RANCANG BANGUN SIMULASI PENGENDALI LAMPU LALU LINTAS PADA PERSIMPANGAN DENGAN LIMA JALUR - 30-39

Rahma Farah Ningrum, Puji Catur Siswipraptini, \& Rosida N. Aziza

6. PERANCANGAN PROGRAM APLIKASI PENGENALAN WAJAH DENGAN MENERAPKAN METODE PRINCIPAL COMPONENT ANALYSIS DAN JARINGAN SYARAF TIRUAN - 40-49

M. Lutfi Aksani

7. KAJIAN PENERAPAN SI / TI DALAM MENINGKATKAN KUALITAS PEMBELAJARAN PADA TRAINING CENTER DENGAN MENGGUNAKAN METODOLOGI DeLone And McLean: STUDI KASUS PADA BINUS CENTER JAKARTA - 50-62 Nyoman Ayu Gita Gayatri \& GG Faniru Pakuning Desak

8. RANCANG BANGUN APLIKASI PEMBELAJARAN MATEMATIKA SD KELAS 6 BERBASIS ANDROID PADA SDN CIMONE 1 TANGERANG - 63-69

Winda Anggraeni \& Sri Mulyati

9. RANCANG BANGUN MESIN PERAJANG SINGKONG INDUSTRI RUMAHAN BERDAYA RENDAH - 70-76

Yafid Effendi \& Agus Danang Setiawan

10. RANCANG BANGUN TONGKAT ULTRASONIK UNTUK PENYANDANG TUNA NETRA BERBASIS ARDUINO UNO - 77-82

Bayu Purnomo \& Basuki Isnanto

11. ENTERPRISE RISK MANAGEMENT PADA CLOUD COMPUTING - 83-87

Samudera Dipa Legawa

12. ANALISIS NETWORK PLANNING DENGAN CRITICAL PATH METHOD (CPM) PADA PROYEK UNINTERATUBLE POWER SUPPLY (UPS) 80KVA PADA PT. HARMONI MITRA SUKSES (STUDI KASUS: RSAB HARAPAN KITA, JAKARTA) - 88-97

Hermanto, Novy Fauziah, \& Elfitria Wiratmani 


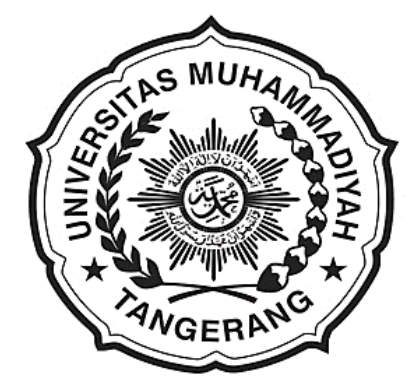

\section{Sambutan Dekan \\ Fakultas Teknik \\ Universitas Muhammadiyah Tangerang}

Puji Syukur kehadirat Allah Swt. karena berkat karunia dan ijin-Nyalah Tim penyusun Jurnal Teknik Fakultas Teknik Universitas Muhammadiyah Tangerang dapat menyelesaikan tugasnya tepat sesuai dengan waktu ditetapkan.

Saya menyambut baik diterbitkannya Jurnal Teknik Vol. 6 No. 1, Januari-Juni 2017, terbitnya jurnal ini, merupakan respon atas terbitnya Peraturan Menteri Pendidikan Nasional No. 17 Tahun 2010 tentang Pencegahan dan Penanggulangan Plagiat di Perguruan Tinggi; Surat Dirjen Dikti Nomor 2050/E/T/2011 tentang kebijakan unggah karya ilmiah dan jurnal; Surat Edaran Dirjen Dikti Nomor 152/E/T/2012 tertanggal 27 Januari 2012 perihal publikasi karya ilmiah yang antara lain menyebutkan untuk lulusan program sarjana terhitung mulai kelulusan setelah 2012 harus menghasilkan makalah yang terbit pada jurnal ilmiah.

Terbitnya Jurnal ini juga diharapkan dapat mendukung komitmen dalam menunjang peningkatan kemampuan para dosen dan mahasiswa dalam menyusun karya ilmiah yang dilandasi oleh kejujuran dan etika akademik. Perhatian sangat tinggi yang telah diberikan rektor Universitas Muhammadiyah Tangerang khususnya mengenai plagiarism dan cara menghindarinya, diharapkan mampu memacu semangat dan motivasi para pengelola jurnal, para dosen dan mahasiswa dalam menyusun karya ilmiah yang semakin berkualitas.

Saya mengucapkan banyak terimakasih kepada para penulis, para pembahas yang memungkinkan jurnal ini dapat diterbitkan, dengan harapan dapat dimanfaatkan seoptimal mungkin dalam peningkatan kualitas karya ilmiah.

Dekan Fakultas Teknik

Universitas Muhammadiyah Tangerang,

\section{Ir. Saiful Haq, M.Si.}




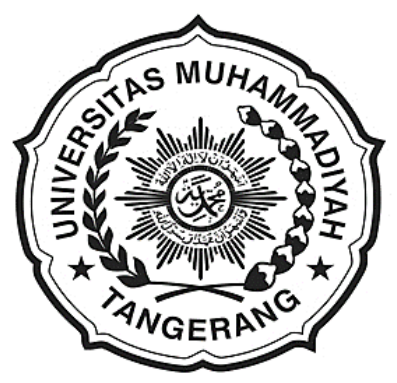

\section{Pengantar Redaksi}

Jurnal Teknik

Universitas Muhammadiyah Tangerang

Puji dan Syukur Alhamdulillah kami panjatkan kehadapan Allah Swt. atas karunia dan lindungan-Nya sehingga Jurnal Teknik Vol. 6 No. 1 edisi Januari-Juni 2017 dapat diterbitkan.

Menghasilkan karya ilmiah merupakan sebuah tuntutan perguruan tinggi di seluruh dunia. Tri Dharma Perguruan Tinggi yaitu darma pendidikan, darma penelitian, dan darma pengabdian kepada masyarakat mendorong lahirnya dinamika intelektual diantaranya menghasilkan karyakarya ilmiah. Penerbitan Jurnal Teknik ini dimaksudkan sebagai media dokumentasi dan informasi ilmiah yang sekiranya dapat membantu para dosen, staf dan mahasiswa dalam menginformasikan atau mempublikasikan hasil penelitian, opini, tulisan dan kajian ilmiah lainnya kepada berbagai komunitas ilmiah.

Buku Jurnal yang sedang Anda pegang ini menerbitkan 12 artikel yang mencakup bidang teknik sebagaimana yang tertulis dalam daftar isi dan terdokumentasi nama dan judul-judul artikel dengan jumlah halaman 1-97 halaman.

Jurnal Teknik ini tentu masih banyak kekurangan dan masih jauh dari harapan, namun demikian tim redaksi berusaha untuk ke depannya menjadi lebih baik dengan dukungan kontribusi dari semua pihak. Harapan Jurnal Teknik akan berkembang menjadi media komunikasi intelektual yang berkualitas, aktual dan faktual sesuai dengan dinamika di lingkungan Universitas Muhammadiyah Tangerang.

Tak lupa pada kesempatan ini kami mengundang pembaca untuk mengirimkan naskah ringkasan penelitiannya ke redaksi kami. Kami sangat berterimakasih kepada semua pihak yang telah membantu penerbitan Jurnal Teknik ini semoga buku yang sedang Anda baca ini dapat bermanfaat.

Pimpinan Redaksi Jurnal Teknik

Universitas Muhammadiyah Tangerang,

Ir. Sumardi Sadi, S.Pd., ST., MT. 


\title{
RANCANG BANGUN APLIKASI PEMBELAJARAN MATEMATIKA SD KELAS 6 BERBASIS ANDROID PADA SDN CIMONE 1 TANGERANG
}

\author{
Winda Anggraeni, Sri Mulyati \\ Program Studi Teknik Informatika \\ Universitas Muhammadiyah Tangerang \\ Jl. Perintis Kemerdekaan I/33, Cikokol - Tangerang-Banten \\ E-mail: lilysrimulyati@gmail.com
}

\begin{abstract}
ABSTRAK
Matematika merupakan ilmu yang mencakup aplikasi yang luas dalam aspek kehidupan. Oleh karena itu inovasi dalam pembelajaran dan strategi pembelajaran matematika perlu dilakukan. Tujuan dari penelitian ini adalah membuat suatu aplikasi pembelajaran matematika yang mampu melatih pengetahuan, keterampilan dan ketepatan dengan cara yang lebih menarik, berupa penggunakan sistem berbasis android. Aplikasi ini dibuat dengan metode SDLC (System Development Life Cycle) yaitu metode yang memaparkan siklus hidup pengembangan sistem informasi. Hasil perancangan pertama yaitu aplikasi Pembelajaran Matematika kelas VI SD yang berisi menu materi, yaitu cara penyelesaian soal atau contoh soal, yang berisi materi diantaranya: Bilangan bulat, Satuan debit, Menghitung luas dan volume, Pecahan, Pengolahan data, dan system koordinat. Isi aplikasi yang kedua yaitu menu latihan soal berisi kumpulan soal matematika pilihan ganda yang menjadi bahan latihan, yang nanti dapat menjadi sebuah aplikasi untuk evaluasi kemampuan siswa dibidang matematika. Isi aplikasi yang ketiga yaitu menu penggunaan aplikasi berisi informasi tentang cara menggunakan aplikasi untuk mempermudah siswa dalam menjalankannya. Isi aplikasi yang keempat yaitu menu tentang berisi informasi tentang aplikasi pembelajaran matematika. Isi aplikasi yang kelima yaitu menu keluar berfungsi untuk keluar dari aplikasi pembelajaran matematika.
\end{abstract}

Kata Kunci: Berbasis Android, Matematika, SDLC (System Development Life Cycle), Kelas VI SD, Aplikasi Pembelajaran.

\section{PENDAHULUAN}

Belajar merupakan suatu proses interaksi antara pemberian ilmu sebagai guru dengan penerimanya sebagai murid, sedangkan kegiatan pembelajaran merupakan bentuk penyelenggaraan pendidikan yang memadukan secara sistematis dan berkesinambungan antara kegiatan pendidikan di dalam lingkungan sekolah dengan kegiatan pendidikan yang dilakukan di luar lingkungan sekolah dalam wujud penyediaan beragam pengalaman belajar untuk semua peserta didik.

Metode pembelajaran akan selalu mengalami perubahan dengan mengikuti perkembangan zaman yang terjadi, salah satu sebab yang mempengaruhi perkem- bangan pembelajaran adalah kecanggihan teknologi. Tujuan utama dari perubahan itu adalah untuk mengadakan pembaharuan guna meningkatkan minat belajar siswa.

Metode pembelajaran dulu yang memiliki peranan penting adalah guru sedangkan yang sekarang berpusat pada siswa, karena terlihat secara jelas bahwa yang melakukan pembelajaran adalah siswa. Dan media pembelajaran yang digunakan selama ini berupa gambar-gambar dan alat peraga berupa benda yang terkadang kurang menarik sehingga kadang siswa malas untuk mengikuti pelajaran dan membuat proses belajar mengajar menjadi tidak kondusif. Untuk itu perlu dilakukan perubahan agar pembelajaran menjadi lebih menarik dan 
menyenangkan bagi siswa.

Pembaharuan yang dilakukan disini adalah memperbaiki metode pembelajaran itu sendiri agar proses pembelajaran yang dilakukan antara guru dan siswa dapat tersampaikan secara maksimal. Dalam hal ini, penulis mengacu pada meode pembelajaran yang kreatif dan inovatif.

Salah satu pembelajaran yang menarik dengan menggunakan alat bantu smartphone sebagai salah satu bentuk teknologi canggih yang dapat digunakan untuk membantu melaksanakan pembelajaran. Smartphone dapat digunakan sebagai alat bantu untuk pembelajaran berbagai mata pelajaran, salah satu diantaranya adalah mata pelajaran matematika. Dalam pelajaran matematika terdapat materi pelajaran diantaranya adalah bilangan bulat, satuan debit, menghitung luas dan volume, pengolahan data, pecahan, dan system koordinat.

Untuk menyampaikan materi pembelajaran yang lebih menarik dalam hal ini menghubungkan antara materi pembelajaran matematika ini dengan teknologi yang marak dibicarakan akhir-akhir ini yaitu Smartphone Android. Android merupakan suatu kecanggihan teknologi sebagai system operasi yang berbasis linux dan dipasang di smartphone. Dengan teknologi ini, merupakan penggambungkan penyampaikan materi pembelajaran matematika dengan Android menjadi sebuah aplikasi.

\subsection{Tujuan dan Manfaat Penelitian}

Tujuan dari penelitian ini adalah: Untuk mengetahui metode pembelajaran matematika saat ini. Untuk mengetahui perancangan aplikasi pembelajaran matematika berbasis android. Untuk mengetahui pengujian pada aplikasi pembelajaran matematika. Untuk mengetahui pengimplementasian pada aplikasi pembelajaran matematika. Manfaat penelitian ini dapat dibedakan menjadi dua bagian yaitu manfaat praktis dan manfaat akademis yang akan dijelaskan sebagai berikut: Bagi Guru, Penelitian tentang aplikasi pembelajaran matematika berbasis android ini diharapkan menjadi bahan referensi guru dalam menyampaikan pelajaran kepada siswa yang lebih kreatif dan inovatif. Bagi siswa Penelitian tentang aplikasi pembelajaran matematika berbasis android ini diharapkan menambahminat belajar siswa dan dapat mudah memahami dalam mempelajari mata pelajaran matematika pada materi matematika.

\section{LANDASAN TEORI}

\subsection{Perancangan}

Menurut Jogiyanto (1991) perancangan adalah suatu jaringan kerja yang saling berhubungan untuk menentukan bagaimana suatu sistem menyelesaikan apa yang mesti diselesaikan. Menurut Kadir (2003) perancangan adalah proses penerapan berbagai teknik dan prinsip dengan tujuan untuk mentransformasikan hasil analisa kedalam bentuk yang memudahkan mengimplementasikan. Menurut Susanto (2004) menjelaskan bahwa perancangan adalah spesifikasi umum dan terinci dari pemecahan masalah berbasis komputer yang telah dipilih selama tahap analisis. Menurut Ladjamudin (2013) tahapan perancangan desain (design) memiliki tujuan untuk mendesain sistem baru yang dapat menyelesaikan masalah-masalah yang dihadapi perusahaan yang diperoleh dari pemilihan alternatif sistem yang terbaik. Kegiatan yang dilakukan dalam tahap perancangan ini meliputi perancangan output, input, dan file. Perancangan Keluaran (Output) adalah Peran-angan keluaran bertujuan menentukan keluaran-keluaran yang akan digunakan oleh sistem. Keluaran tersebut berupa tampilantampilan layar, dan juga format dan frekuensi laporan yang diperlukan. Perancangan Masukan (Input) adalah Perancangan masukan bertujuan menentukan data-data masukan, yang akan digunakan untuk mengoperasikan system. Data-data masukan tersebut dapat berupa formulir-formulir, faktur, dan lain-lain yang berfungsi memberikan data masukan bagi pemrosesan sistem. Pada tahap ini perlu juga ditentukan format data masukan agar sesuai dengan kebutuhan system.

\subsection{Aplikasi}

Aplikasi berasal dari kata application yang artinya penerapan, lamaran penggunaan. Secara istilah aplikasi adalah program siap pakai yang dibuat untuk melaksanakan suatu fungsi bagi pengguna atau aplikasi yang lain dan dapat digunakan oleh sasaran 
yang dituju. Menurut Jogianto (1999:12) adalah penggunaan dalamsuatu computer, instruksi (instruction) atau pernyataan (statement) yang disusun sedemikian rupa sehingga computer dapat memproses input menjadi output. Menurut kamus besar Bahasa Indonesia (1998:52) adalah penerapan dari rancang system untuk mengolah data yang menggunakan aturan atau ketentuan bahasa pemrograman tertentu. Aplikasi adalah suatu program computer yang dibuat untuk mengerjakan dan melaksanakan tugas khusus dari pengguna. Menurut Rachmad Hakim S, adalah perangkat lunak yang digunakan untuk tujuan tertentu, seperti mengolah dokumen, mengatur Windows dan permainan (game), dan sebagainya. Menurut Harip Santoso, adalah suatu kelompok file (form, class, report) yang bertujuan untuk melakukan aktivitas tertentu yang saling terkait, misalnya aplikasi payroll, aplikasi fixed asset. Menurut Hendrayudi, aplikassi adalah kumpulan perintah program yang dibuat untuk melakukan pekerjaan-pekerjaan tertentu. Menurut Hengky W.Pramana, adalah suatu unit perangkat lunak yang dibuat untuk melayani kebutuhan akan beberapa aktivitas tertentu yang saling terkait. Menurut Ibisa, adalah alat bantu untuk mempermudah dan mempercepat proses pekerjaan dan bukan merupakan beban bagi penggunanya.

\subsection{Pengertian Pembelajaran}

Belajar adalah sebuah proses perubahan didalam kepribadian manusia dan perubahan tersebut ditampakkan dalam bentuk peningkatan kualitas dan kuantitas tingkah laku seperti peningkatan kecakapan, pengetahuan, sikap, kebiasaan, pemahaman, keterampilan, daya piker, dan kemampuan-kemampuan yang lain.

Berikut ini adalah penngetahuan dan definisi belajar menurut beberapa ahli: Slameto (2003:2), suatu proses usaha yang dilakukan seseorang untuk memperoleh suatu perubahan tingkah laku yang baru secara keseluruhan, sebagai hasil pengalamannya sendiri dalam interaksi dengan lingkungannya. Trianto (2010:16), proses belajar terjadi melalui banyak cara baik disengaja maupun tidak disengaja dan berlangsung sepanjang waktu dan menuju pada suatu perubahan pada diri pembelajar. Ngalim Purwanto (1992:84), setiap perubahan yang relative menetap dalam tingkah laku, yang terjadi sebagai suatu hasil dari latihan atau pengalaman.

\subsection{Pengertian Matematika}

Matematika berasal dari bahasa latin manthanein atau mathema yang berarti belajar atau hal yang dipelajari. Matematika dalam bahasa Belanda disebut wiskunde atau ilmu pasti, yang kesemuanya berkaitan dengan penalaran. Ciri utama matematika adalah pealaran deduktif, yaitu kebenaran suatu konsep atau pernyataan diperoleh sebagai akibat logis dari kebenaran sebelumnya sehingga kaitan antar konsep atau pernyataan dalam matematika bersifat konsisten. Sujono (1988:5) mengemukakan beberapa pengertian matematika. Diantaranya, matematika diartikan sebagai cabang ilmu pengetahuan tentang penalaran yang logic dan masalah yang berhubungan dengan bilangan

\section{METODE PENELITIAN}

\subsection{Metode Pengumpulan Data}

Untuk mendapatkan data yang diperlukan dalam penulisan laporan tugas akhir ini penulis menggunakan dua jenis data pada penelitian, antara lain:

Data Primer, merupakan sumber data yang diperoleh secara langsung dari sumber aslinya (tidak melalui media perantara). Data primer berupa Metode Observasi $(\mathrm{Ob}$ servation Research) dan Metode Wawancara (Interview Research)

Data Sekunder, yaitu merupakan sumber data penelitian yang diperoleh secara tidak langsung melalui media perantara (diperoleh dan dicatat oleh pihak lain). Data sekunder berupa Metode Pustaka (Library Research)

Untuk melengkapi dan mendukung materi dalam uraian pembahasan, dibutuhkan sejumlah data atau informasi yang berkaitan dengan penelitian karya ilmiah ini. Oleh karena itu, penulis melakukan penelitian guna mendapatkan data yang real sesuai referensi yang diperlukan. Esensial dalam metode ini bertujuan untuk melengkapi proses penelitian selanjutnya. Metode ini meliputi penelitian lapangan (observasi, wa- 
wancara dan kuesioner) dan studi pustaka.

\subsection{Metode Pengembangan Sistem}

Dalam pengembangan system atau perancangan sebuah aplikasi, tentunya terdapat metode pengembangan system didalamnya. Ada beberapa metode dalam pengembangan sebuah sistem, dalam penulisan tugas akhir ini, penulis menggunakan metode System Development Life Cycle (SDLC).

System Development Life Cycle (SDLC) adalah suatu pendekatan yang memiliki tahap atau bertahap untuk melakukan analisa dan membangun suatu rancangan sistem dengan menggunakan siklus yang lebih spesifik terhadap kegiatan pengguna (Kendall \& Kendall, 2006). Metode SDLC adalah metode yang menggunakan pendekatan sistem yang disebut pendekatan air terjun (waterfall approach) dimana setiap tahapan sistem akan dikerjakan secara berurut menurun dari perencanaan, analisa, desain, implementasi, dan perawatan (Aji Supriyanto, 2005: 272 ). Siklus hidup pengembangan sistem (System Development Life Cycle / SDLC) merupakan suatu bentuk yang digunakan untuk menggambarkan tahapan utama dan langkah-langkah di dalam tahapan tersebut untuk proses pengembangannya. Siklus hidup pengembangan system merupakan proses evolusioner yang diikuti dalam menerapkan sistem atau subsistem informal berbasis komputer. SDLC dilakukan dengan pendekatan sistem secara teratur dan dilakukan secara topdown, oleh karenanya sering disebut pendekatan air terjun (waterfall approach) bagi pengembangan dan penggunaan sistem.

\section{a. Tahapan SDLC}

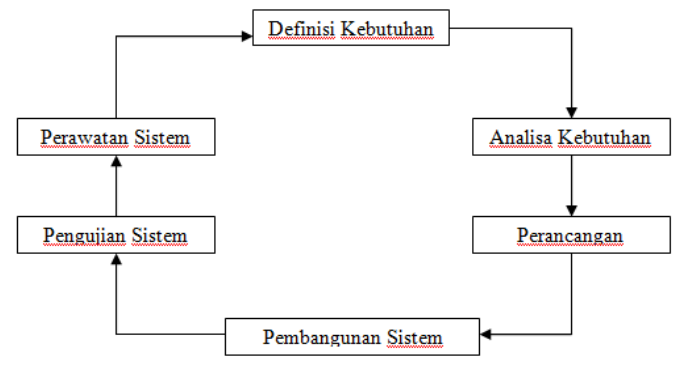

Gambar 3.1 flowchart SDLC.

Setiap pengembang mempunyai strategi yang berlainan, namun demikian pada dasarnya siklus hidup pengembangan sistem informasi terdapat 5 (lima) tahapan, yaitu:

1). Tahapan definisi kebutuhan

Adalah proses perencanaan kebutuhan aplikasi terhadap user. Dilakukan pula pengelompokkan permasalahan yang terjadi sebelum aplikassi dibangun sehingga dapat dilakukan penilaian terhadap kebutuhan baru.

\section{2). Tahapan analisis kebutuhan}

Yaitu mencari dan menganalisis kebutuhan user, baik berupa informasi maupun perangkat yang digunakanserta aplikasi disesuaikan dengan kebutuhan user, kemusian memberikan alternatife terbaik tentang aplikasi yang digunakan oleh user untuk mempermudah kinerja user.

\section{3). Tahapan perancangan atau desain}

Merupakan perancangan user interface design yang meliputi tampilan, form dan desain dari Aplikasi Pembelajaran Matematika.

4). Tahapan pembangunan system (coding)

Merupakan tahapan implementasi dari tahap perancangan yang secara teknisnya dikerjakan oleh programmer. Setelah perancangan selesai, maka Aplikasi dibangun dengan menggunakan software eclipse.

5). Pengujian sistem

Merupakan tahapan uji coba terhadap aplikasi media pembelajaran sebelum aplikasi dapat digunakan sepenuhnya. Seluruh fungsi-fungsi dari aplikasi harus diuji coba agar system terbebas dari error dan hasilnya sesuai dengan kebutuhan user.

\section{6). Tahapan perawatan}

Tahapan perawatan aplikasi terjadi modifikasi software, perbaikan dari error atau umpan balik dari user terhadap aplikasi yang telah digunakan. Pemeliharaan suatu aplikasi diperlukan, termasuk didalamnya pengembangan dari apliaksi dengan penambahan fitur-fitur baru untuk mendapatkan hasil yang maksimal.

\section{b. Objek Penelitian}

Penelitian ini dilakukan di Ruang Guru SDN Cimone 1 Tangerang. Yang bertempat di Jl. Proklamasi no. 14 Tangerang Banten. Objek Penelitian berupa: Sejarah Singkat Sekolah,Visi Misi dan Sarana Prasaran.

1). Sejarah Singkat Sekolah

SDN Cimone 1 berdiri pada tahun 1979, merupakan pemekaran dari SDN 
Cimone 1 Tangerang Kelurahan Cimone Kecamatan Karawaci yang beralamat Jl. Proklamasi no. 14 Kota Tangerang Banten.

Pada saat berdiri kondisi sekolah awalnya mempunyai 4 ruang kelas, 1 ruang serbaguna, 1 ruang kepala sekolah, dan 1 ruang guru.

Untuk mencapai kesuksesan lainnya, makakami perlu membuat rencana pengembangan sekolah yang matang atau kerja sekolah yang menitik beratkan kepada pengembangan diri setiap hari Sabtu diantaranya:

Pramuka, Pencak Silat, Marawis, Kegiatan Olahraga Futsal dan Bulu Tangkis, kegiatan pengembangan diri tersebut kami yakini dapat member warna tersendiri bagi kemajuan di SDN Cimone 1.

\section{2). Visi dan Misi Sekolah}

Visi sekolah adalah unggul dalam prestasi, disiplin dan bertanggung jawab, pelopor dalam imtek dan imtaq, teladan dalam bersikap dan berkarakter. Misi sekolah adalah mewujudkan peningkatan kualitas tamatan, membentuk generasi yang bertakwa, mandiri, memiliki sikap gotong royong, kekeluargaan dan cinnta tanah air. Membentuk generasi yang cerdas, terampil, kreatif, berdedikasi yang tinggi dan cinta almamater. Meningkatkan semangat dan prestasi kerja yang dilandasi dengan rasa tanggung jawab dan berkarakter bangsa. Menciptakan keselarasan, keseimbangan emosi dan intelektual dalam mewujudkan situasi kondusif terhadap terwujudnya tujuan pendidikan nasional.

\section{3). Sarana dan Prasarana}

Sarana dan prasarana adalah unsur yang sangat dibutuhkan dalam proses belajar mengajar, hal ini disebabkan karena fungsinya sebagai alat yang digunakan untuk memperlancar proses kegiatan tersebut. Ditinjau dari pengertian secara umum sarana adalah sesuatu yang dipakai sebagai alat dalam mencapai maksud dan tujuan (media), sedangkan prasarana adalah segala sesuatu yang merupakan penunjang utama terselenggaranya suatu proses, usaha atau kegiatan.
Tabel 1 Sarana dan Prasarana

\begin{tabular}{|c|l|c|l|}
\hline No. & $\begin{array}{c}\text { Jenis Sarana dan } \\
\text { Prasaran }\end{array}$ & Jumlah & Ket. \\
\hline 1 & Ruang Kelas & 6 & Ruangan \\
\hline 2 & Ruang Guru & 1 & Ruangan \\
\hline 3 & $\begin{array}{l}\text { Ruang Kepala } \\
\text { Sekolah }\end{array}$ & 1 & Ruangan \\
\hline 4 & $\begin{array}{l}\text { Labolatorium } \\
\text { Komputer }\end{array}$ & 1 & Ruangan \\
\hline 5 & Toilet Guru & 1 & Ruangan \\
\hline 6 & Toilet Siswa & 2 & Ruangan \\
\hline 7 & Lapangan Upacara & 1 & Ruangan \\
\hline 8 & $\begin{array}{l}\text { Lapangan Olahraga } \\
\text { dan Bermain }\end{array}$ & 1 & Ruangan \\
\hline 9 & Gudang & 1 & Ruangan \\
\hline 10 & Komputer & 10 & Buah \\
\hline 11 & Internet & 1 & Buah \\
\hline 12 & Megaphone & 1 & Buah \\
\hline 13 & Radio & 2 & Buah \\
\hline 14 & Angklung & 1 & Buah \\
\hline 15 & Infocus & 1 & Buah \\
\hline 16 & Gitar & & \\
\hline
\end{tabular}

\section{ANALISIS DAN PEMBAHASAN}

\subsection{Implementasi Sistem}

Halaman Informasi terdiri dari: Halaman Menu Utama, Materi dan Soal, Penggunaan Aplikasi, dan Score.

1. Halaman Menu Utama

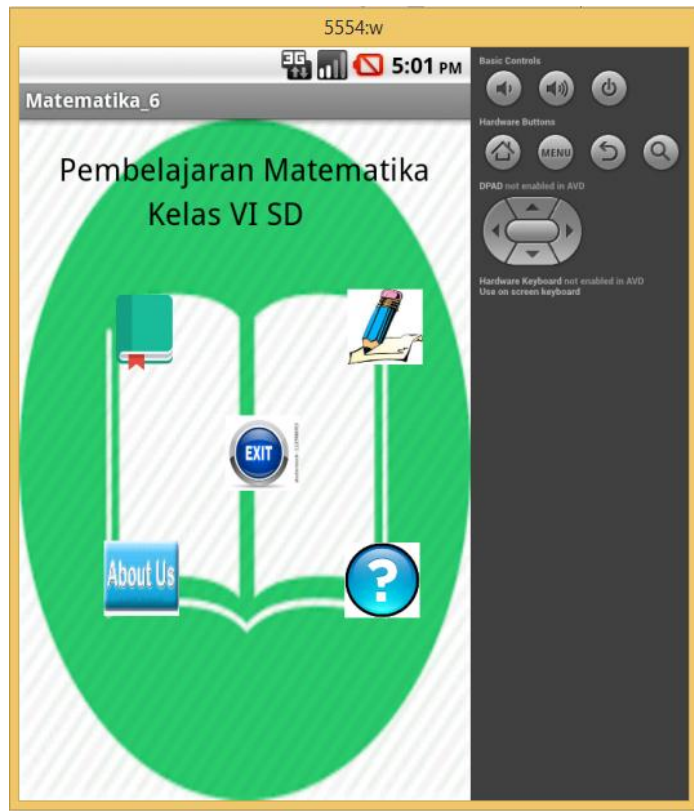

Gambar 4.29 Halaman Menu Utama 


\section{Halaman Materi}

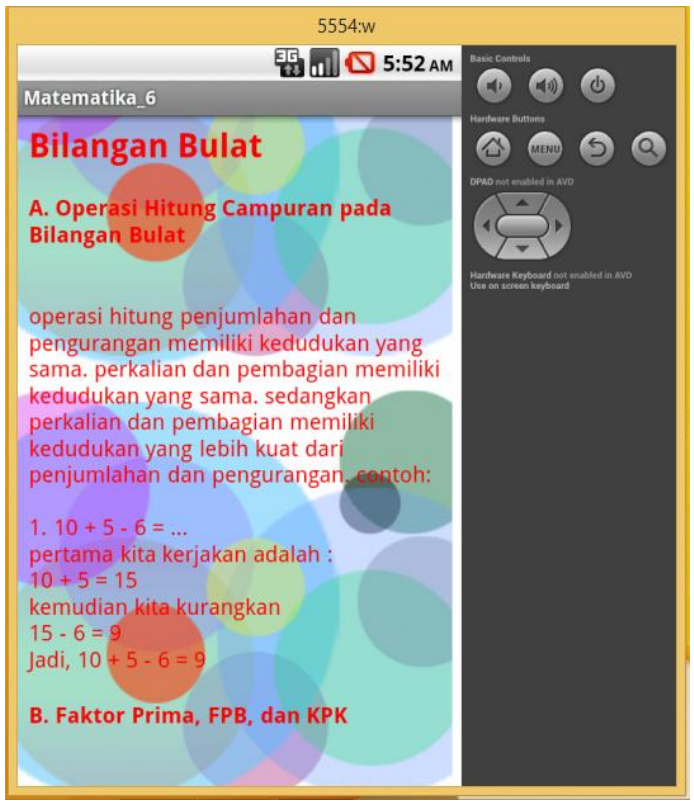

Gambar 4.30 Halaman Materi

3. Halaman Latihan Soal

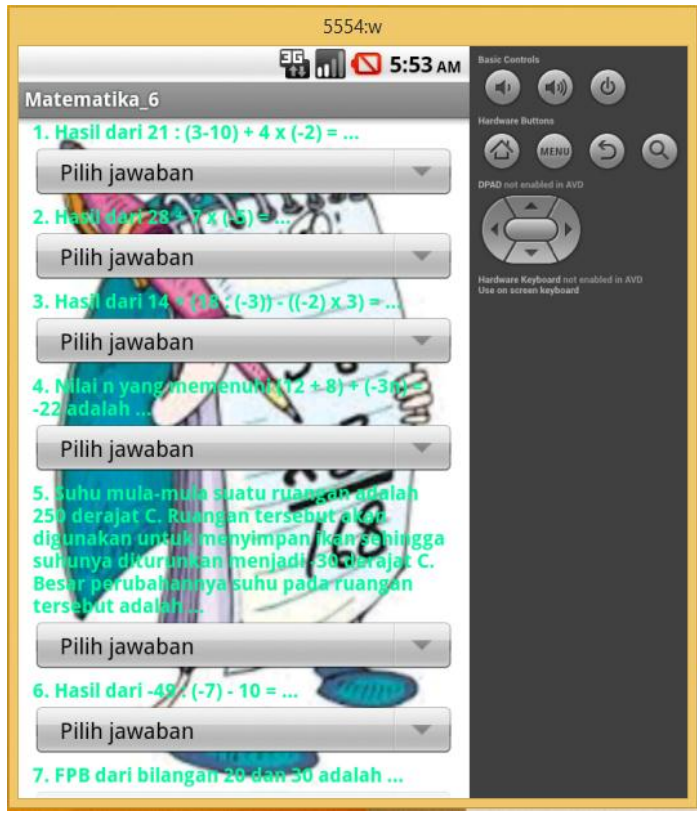

Gambar 4.31 Halaman Latihan Soal
4. Halaman Penggunaan Aplikasi

Matematika_6
Penggunaan Aplikasi
Silahkan Anda pilih Menu Utama.
Menu
Merdapat 5 menu di halaman menu ini.
1. Pilih materi.
2. Lalu akan tampil daftar materi yang
tersedia.
3. Lalu pilih materi yang ingin Anda
baca.
4. Terima kasih.
Latihan Soal
1. Pilih latihan soal.
2. Lalu akan tampil daftar latihan soal
vang tersedia.
Gambar 4.32 Halaman Penggunaan

Gambar 4.32 Halaman Penggunaan Aplikasi

\section{Halaman Tentang Aplikasi}

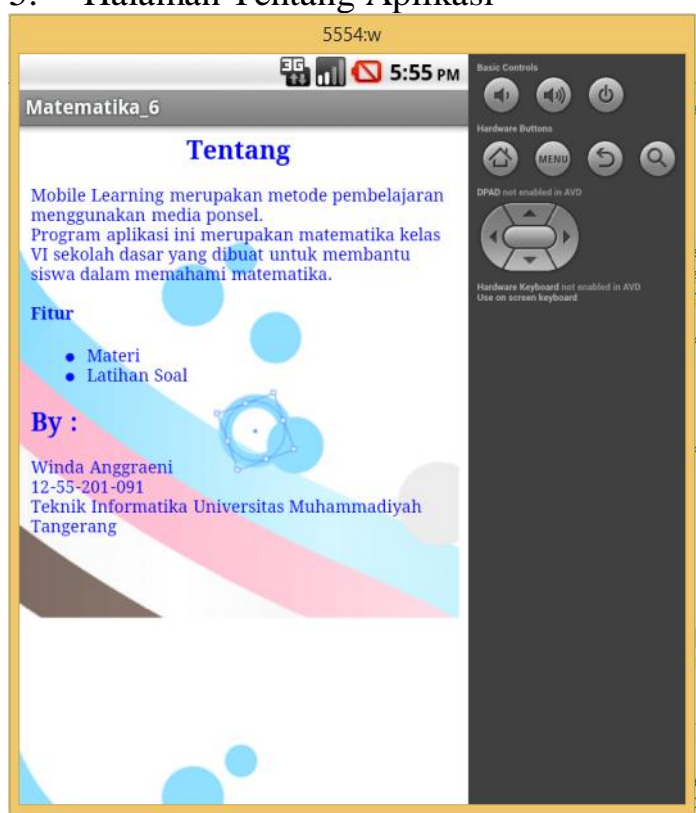

Gambar 4.33 Halaman Tentang Aplikasi 
6. Halaman Score

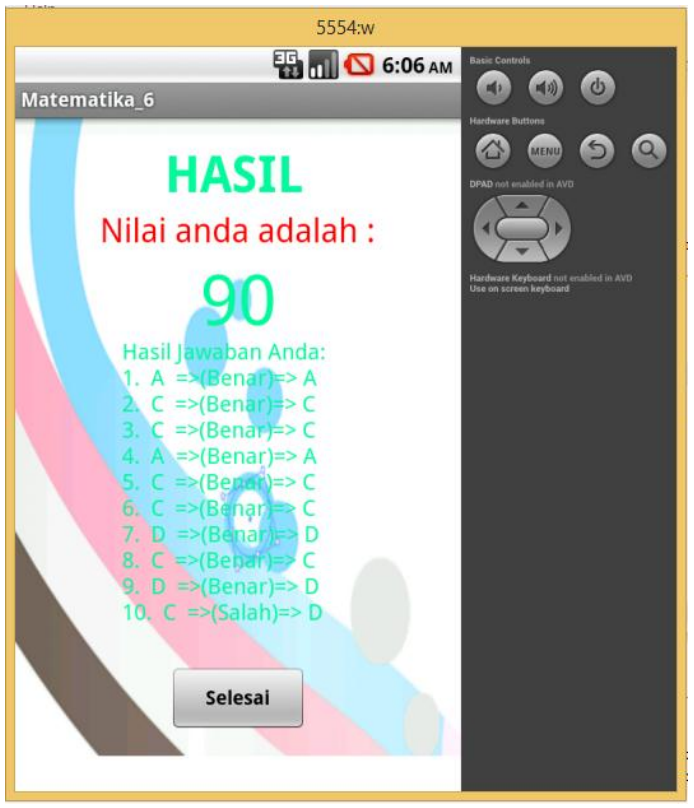

Gambar 4.34 Halaman Score

\subsection{Pengujian Sistem}

Setiap program menjalani pengujian secara pribadi memastikan bahwa program yang di develop bebas dari kesalahan (bug), walaupun tidak menutup kemungkinan masih sedikit bug atau tidak $100 \%$ bebas dari bug, namun pengujian ini setidaknya bisa meminimalisasi kesalahan yang akan terjadi.

Pengujian secara black box, yaitu suatu pendekatan untuk menguji apakah setiap fungsi didalam program dapat berjalan dengan benar. Berikut tabel hasil pengujian dari aplikasi pembelajaran matematika.

Tabel 2 Hasil pengujian dengan pendekatan black box

\begin{tabular}{|c|l|l|}
\hline No & \multicolumn{1}{|c|}{ Proses } & \multicolumn{1}{|c|}{ Hasil } \\
\hline 1 & Menu Materi & Berhasil \\
\hline 2 & Menu Latihan Soal & Berhasil \\
\hline 3 & Menu Penggunaan Aplikasi & Berhasil \\
\hline 4 & Menu Tentang Aplikasi & Berhasil \\
\hline 5 & Hitung Skor & Berhasil \\
\hline 6 & Halaman Menu Utama & Berhasil \\
\hline
\end{tabular}

\section{PENUTUP}

Setelah menganalisa aplikasi yang dibuat, dapat disimpulkan bahwa:

1. Materi-materi yang ada dalam modul dapat diintegrasikan dalam sebuah aplikasi pembelajaran sehingga tidak ada materi-materi yang terpisah. Dengan adanya unsur multimedia dalam aplikasi pembelajaran ini membuat siswa kelas 6 SDN Jatake 1 dalam mempelajari matematika; dan

2. Hasil akhir dari penelitian ini berupa aplikasi belajar matematika kelas 6 berbasis android.

\section{DAFTAR PUSTAKA}

http://repository.uinjkt.ac.id/dspace/bitstrea m/123456789/20733/1/DEWI\%20Y ULIARTI-FST.pdf (akses 10 Maret 2016)

https://yuliagroups.wordpress.com/systemdevelopment-life-cycle-sdlc/

\(akses 01 Juni 2016)

http://vicrimarzak.blogspot.co.id/2012/11/m ateri-sdlc.html (akses 01 Juni 2016)

http://lukluulmarjan.blogspot.co.id/2013/04/ sdlc-system-development-lifecycle.html (akses 01 Juni 2016)

Android Tim HLIndo (2015). Aplikasi Android Soal Pilihan Ganda. PT Elex Media Komputindo. Jakarta

http://adampratama.blogdpot.com/2007/09/p engertian-uml-unified-modeling / (akses 4 Maret 2016).

Irawan(2014). Aplikasi Android dengan Eclipse. Maxikom. Palembang.

EMS Tim (2015). Pemrograman Android dalam Sehari. PT. Elex Media Komputindo. Jakarta. 